\title{
ANÁLISE COMPARATIVA DE CORTES DE ENCÉFALOS HUMANOS COM COLORAÇÃO POR TRÊS TÉCNICAS DIFERENTES
}

\author{
Murilo Sousa de Meneses ${ }^{1}$, Juan Carlos M ontano Pedroso², \\ Rúbia Fátima Fuzza², Jerônimo Buzetti Milano
}

\begin{abstract}
RESUM 0 - 0 estudo anatômico do encéfalo em cortes é facilitado empregando-se métodos de coloração para substância cinzenta. Os métodos mais freqüentemente empregados são os de Barnard, Robert e Brown, Mulligan e Green. 0 objetivo deste estudo foi determinar qual dessas técnicas apresenta melhores resultados com relação à diferenciação entre substâncias branca e cinzenta. Trinta cortes coronais de hemisfério cerebral humano foram submetidos às três técnicas, comparados entre si e analisados de acordo com três parâmetros estabelecidos: grau de diferenciação entre as substâncias branca e cinzenta; presença de linha única e contínua separando a substância branca do córtex cerebral; grau de impregnação da coloração em outros locais de substância branca. Atribuíram-se pontuações de 0 a 3 conforme a presença destes parâmetros, cada corte recebendo pontuação total que variava de 0 a 9. Após análise estatística, a técnica de Barnard, Robert e Brown apresentou média 8,33; a de Green 7,93 e a de Mulligan, 7,5, com diferença estatisticamente significativa.
\end{abstract}

PALAVRAS-CHAVE: técnicas de coloração, substância cinzenta, neuroanatomia.

\begin{abstract}
Comparative analysis of human brain slices with three different staining techniques
ABSTRACT - Studing neuroanatomy at brain slices with gray matter staining techniques has several advantages. More often, the models described by Barnard, Robert and Brown, Mulligan, and Green are used. The aim of this study was to identify which of them achieves the best results on differentiation between the gray and the white matter. Thirty coronal slices of human brains underwent staining by the three techniques, and thus compared and analysed according this three parameters: degree of differentiation between white and gray matter, presence of a single and uninterrupted line dividing the white matter from the brain cortex; and degree of impregnation of the color staining in the white matter; scores from 0 to 3 have been given for the three parameters, with total score from 0 to 9. After statistic analysis, the Barnard, Robert and Brown model showed the best results, followed by Green's and Mulligan's.
\end{abstract}

KEY WORDS: staining methods, gray matter, neuroanatomy.

0 estudo de cortes de encéfalo sem técnicas de coloração encontra dificuldades na diferenciação das estruturas de substância cinzenta e de substância branca. Estruturas como 0 cortéx cerebral e os núcleos da base são formadas por substância cinzenta com predomínio de corpos celulares de neurônios. A coroa radiada, a comissura anterior, as cápsulas interna, externa e extrema, entre outras formações, representam a substância branca, formada basicamente pelos axônios de neurônios e correspondendo às vias de projeção e de associação ${ }^{1}$. Em certos casos, vias aferentes e eferentes passam através de núcleos de substância cinzenta. Por exemplo, o globo pálido contém as vias de saída do corpo estriado e é dividido em duas porções, uma lateral ou externa e outra medial ou interna². Desta porção saem vias eferentes ao tálamo e ao núcleo subtalâmico. Tais fibras fazem com que o globo pálido apresente aspecto particular em relação aos demais núcleos da base ${ }^{3}$. A diferenciação detalhada desses núcleos e dessas vias é melhor evidenciada com o emprego de técnicas de coloração do encéfalo.

Apesar da maioria dos laboratórios não empregar métodos de coloração em estudos anatômicos, diferentes meios têm sido descritos para diferenciar as estruturas de substância branca e de substância cinzenta ${ }^{4}$. 0 método de M ainland consiste em submergir cortes de encéfalo sucessivamente em soluções de cloreto férrico, ferrocianeto de potássio e ácido nitrico $0^{5}$. 0 método de Kondratjew é realizado imergindo-se secções de encéfalo em uma solução de anidrido de vanádio,

Departamento de Anatomia da Universidade Federal do Paraná (UFPR), Instituto de Neurologia de Curitiba (INC), Curitiba PR, Brasil: ${ }^{1}$ Neurocirurgião, Doutor em Anatomia, Professor e Chefe do Departamento de Anatomia da UFPR; ${ }^{2}$ M édico; ${ }^{3}$ Residente de Neurocirurgia do INC.

Recebido 13 Junho 2003, recebido na forma final 30 Setembro 2003. Aceito 12 Novembro 2003.

Dr. Murilo Sousa de Meneses - Instituto de Neurologia de Curitiba - Rua Jeremias Maciel Perreto 300 - 81210-310 Curitiba PR - Brasil. 
glicerina e ácido fosfórico, acrescentando-se após ferro pulverizado e vermelho neutro ${ }^{6}$. A técnica de Fujari baseia-se na fixação da peça em formol com sulfato de zinco, seguida da imersão desta em solução de prussiato amarelo de potássio?. 0 método de Mari consiste em submergir cortes de encéfalo em solução de fenol, sulfato de cobre e ácido clorídrico, seguido de imersão em solução de ácido tânico e hipoclorito de sódio ${ }^{4}$. A técnica de Bachi é realizada através da imersão dos cortes de encéfalo em solução de ácido tânico e hipoclorito de sódio4. Contudo, os métodos que vêm sendo utilizados com maior frequêencia nos laboratórios de neuroanatomia, provavelmente devido à praticidade de realização que apresentam, são os métodos de Green ${ }^{4}$, Mulligan 7 e Barnard, Robert e Brown 8 .

0 objetivo do presente estudo foi determinar o melhor método para evidenciar os núcleos da base e as vias de projeção e de associação intra e inter-hemisféricas pelas três técnicas mais utilizadas nos laboratórios de neuroanatomia, ou seja, os métodos de Green, Mulligan e Barnard, Robert e Brown. Não foram encontrados trabalhos científicos na revisão de literatura que comparassem a eficácia de tais técnicas.

\section{MÉTODO}

Vinte encéfalos humanos de individuos adultos brancos foram obtidos no Departamento de Anatomia da Universidade Federal do Paraná e do Serviço de Anatomia Patológica do Hospital de Clínicas da cidade de Curitiba. 0 material foi colocado em solução fixadora de formol a $10 \%$ e em seguida foram retiradas cuidadosamente todas as meninges e os vasos da superfície do encéfalo. Os encéfalos foram então seccionados através de cortes coronais seriados de espessura de $10 \mathrm{~mm}$, apoiando-se o material sobre superfície plana, com auxílio de encéfalótomo devidamente afiado, através de um único movimento, conforme preconizado pela literatura ${ }^{9-12}$. Foram selecionados 60 cortes coronais de encéfalo; 20 destes passavam pela comissura anterior, 20 pelo fascículo mamilo-talâmico e 20 pelo núcleo rubro e substância negra. Tais cortes são clássicos no estudo da neuroanatomia, pois evidenciam as mais importantes formações de substância cinzenta e da substância branca. Cada corte coronal, por sua vez, foi seccionado no plano mediano sagital por um corte único passando pelo corpo caloso e fissura longitudinal do cérebro, totalizando-se quarenta cortes de hemisfério cerebral para cada um dos três níveis. Separaram-se 30 cortes de hemisfério cerebral para cada método, 10 deles passando através de cada nível específico já citado. 0 trabalho foi aprovado pela Comissáo de Ética do Departamento de Anatomia da Universidade Federal do Paraná. Segue-se a descrição das técnicas de coloração aplicadas.

Técnica de Mulligan - Após a lavagem dos cortes em água corrente, deixou-se o material em imersão por dois minutos a uma temperatura de 60-650, na seguinte solução: a solução de Mulligan: Fenol 4,0g; ácido cloridrico 0,125 ml; sulfato de cobre 0,5g; água $100 \mathrm{ml}$. Em seguida fez-se lavagem em água corrente (15 segundos) e subseqüente imersão em solução de ácido tânico a $2 \%$ por um minuto. Após nova lavagem em água corrente, as peças foram colocadas em solução de alúmem de ferro a 0,5\% por aproximadamente um minuto. Fez-se nova lavagem em água corrente e colocaram-se os cortes em solução fixadora de álcool a 70으.L.

Técnica de Green - para a realização desta técnica procedeu-se à preparação de três cubas da seguinte maneira: Cuba 1 - ácido carbólico cristalizado $4 \%$; sulfato de cobre cristalizado $1 / 2 \%$; ácido clorídrico concentrado $1 / 8 \%$. Cuba 2 - ácido tânico 2\%. Cuba 3 alúmen de ferro $2 \%$. Os cortes foram lavados em água corrente e então imersos, durante um minuto, primeiramente na cuba 1 e em seguida na cuba 2 , sendo que, após a retirada de cada cuba, foram lavados em água corrente por 15 segundos. Como a utilização de qualquer material metálico dentro das cubas pode alterar todo 0 processo, foi empregada espátula de plástico. Por último, fez-se a imersão na cuba 3, por quinze segundos seguida de nova lavagem em água corrente.

Técnica de Barnard, Robert e Brown - Os cortes foram imersos na solução de Mulligan previamente aquecida a 60-65으 C, por aproximadamente dois minutos, seguindo-se lavagem em água corrente morna por um minuto. Colocaram-se então os cortes em solução de cloreto férrico a $1 \%$ durante um a três minutos e lavaram-se em água corrente por um minuto. Seguiu-se a imersão dos cortes em solução de ferrocianeto de potássio a $1 \%$ durante um minuto. Lavou-se então o material em água corrente morna por um minuto. Os cortes foram submersos em solução fixadora de formol a $10 \%$ acidificada com ácido clorídrico suficiente para que se obtivesse solução final a 2\%.

A análise dos cortes de encéfalo coloridos foi realizada por acadêmicos do curso de Medicina da Universidade Federal do Paraná, durante a Disciplina de Anatomia M édica II, através da visibilização das estruturas presentes em cada hemisfério de acordo com três parâmetros. 0 parâmetro 1 analisa 0 grau de diferenciação entre as substâncias branca e cinzenta. As técnicas de colocação empregadas realçam essa característica presente no cérebro humano, permitindo maior distinção entre as regiões de substâncias branca e cinzenta. Procurou-se determinar qual das três técnicas melhor servia a este propósito. Para isso analisou-se, em cada hemisfério corado, a área percentual da superfície de corte que mostrava diferenciação mais nítida. Estipulou-se uma pontuação de 0 a 3 para cada corte de hemisfério. A nota 0 foi atribuída aos cortes de hemisfério que apresentaram melhor distinção entre substância branca e cinzenta numa área menor que $25 \%$ da superfície total do corte; nota 1 indica que essa melhor diferenciação foi possível numa área de 25 a $50 \%$ da superfície de corte; nota 2 mostra a maior nitidez da distinção numa área de 50 a $75 \%$; a nota 3, em superfície maior que $75 \%$.

0 parâmetro 2 refere-se à presença de linha única e contínua separando a substância branca do córtex cerebral que a envolve. Ao se realizar técnicas de coloração de substância cinzenta, correse o risco de manchar a linha que delimita naturalmente a substância branca do córtex adjacente a ela. Nesse sentido, procurou-se determinar qual das três técnicas mantinha essa linha com maior fidelidade. Para análise desse parâmetro atribui-se pontuação de 0 a 3 para cada hemisfério. A nota 0 indica presença dessa linha única e contínua em área menor que $25 \%$ da superfície total do corte; a nota 1 mostra presença da linha em área de 25 a $50 \%$ da superfície total do corte; a nota 2, linha em uma área de 50 a $75 \%$ da superfície total de corte; a nota 3, em área maior que $75 \%$.

0 parâmetro 3 indica 0 grau de impregnação da coloração em 


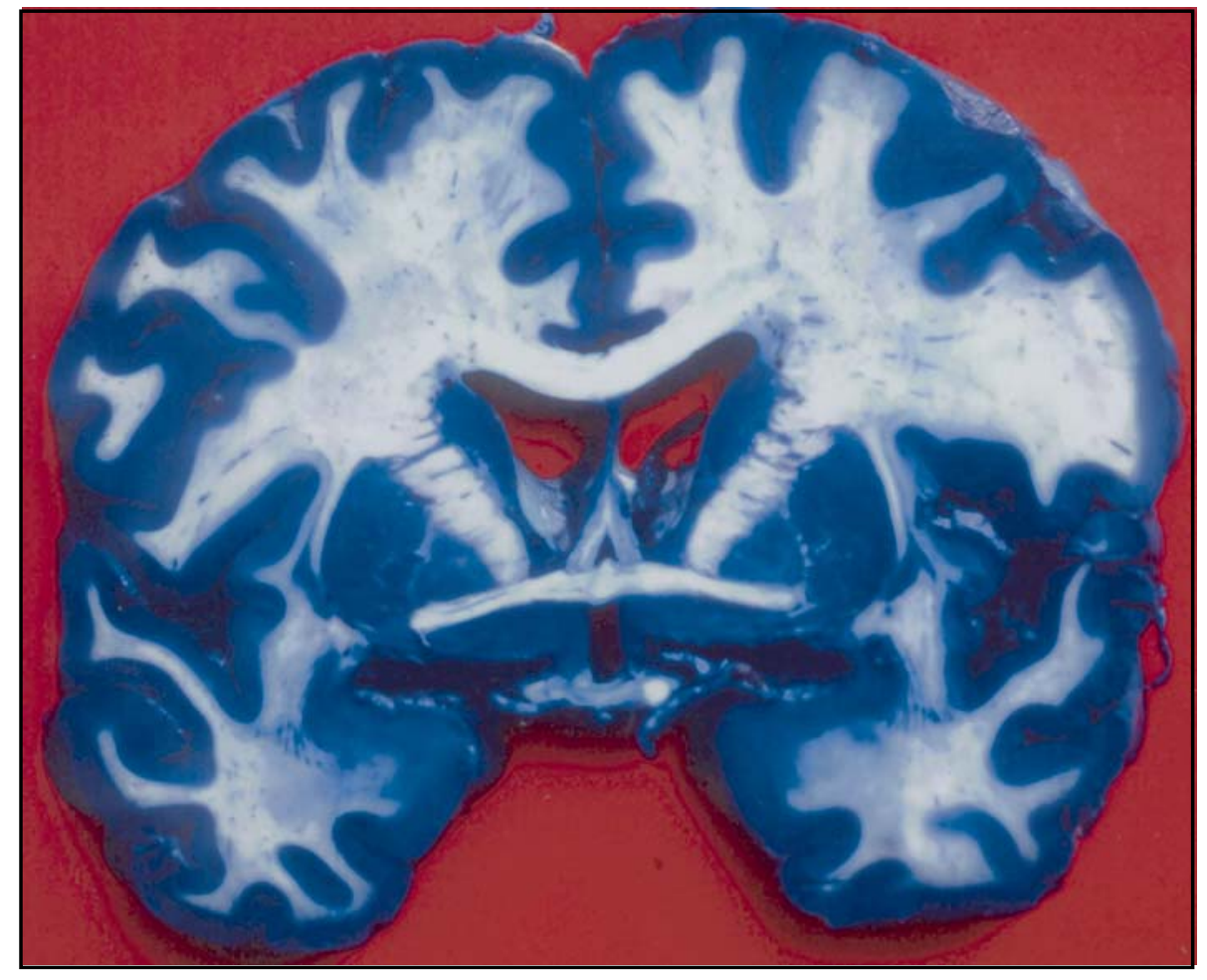

Fig 1. Foto de corte encefálico coronal passando pela comissura anterior, submetido a coloração de Barnard, Robert e Brown.

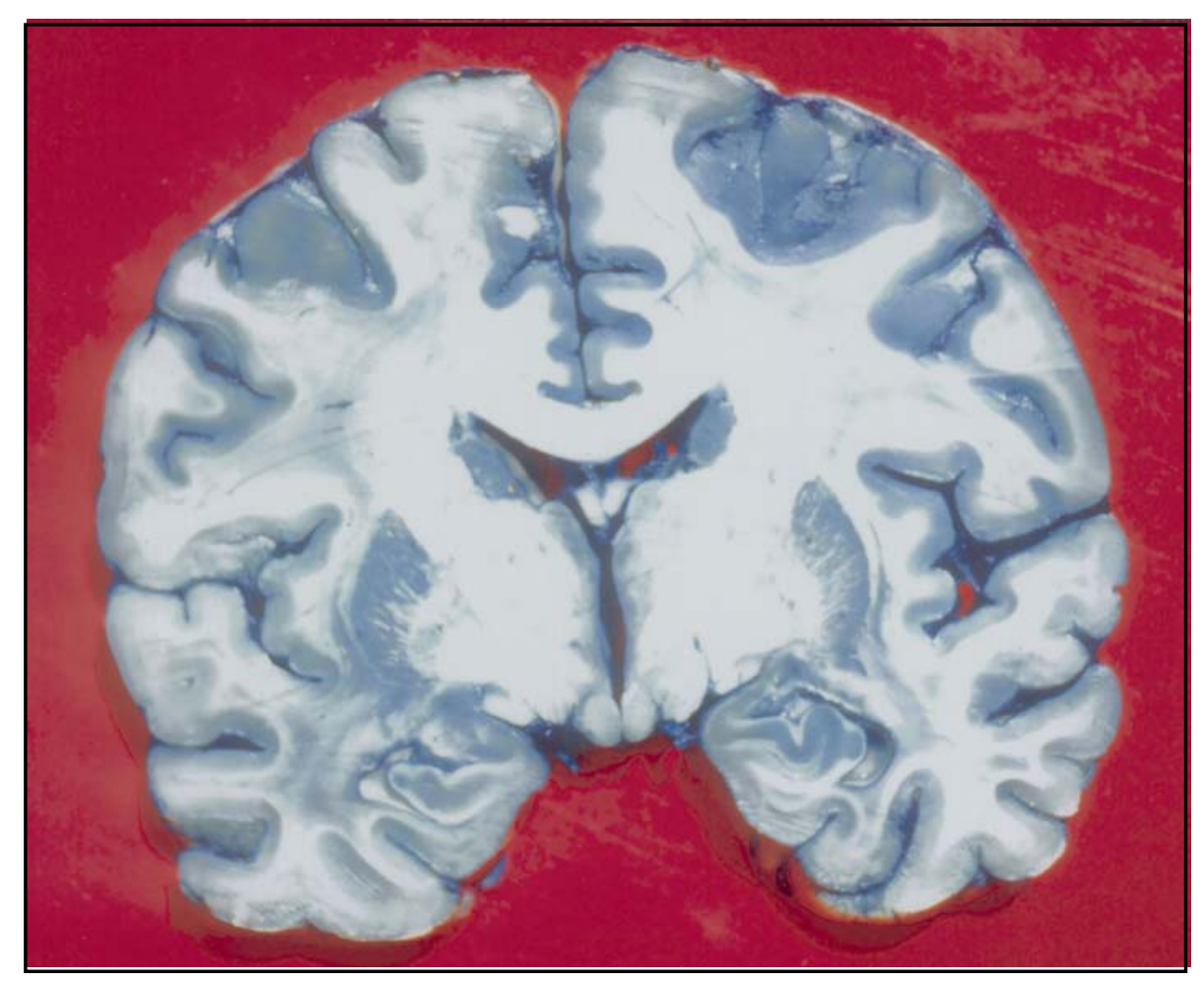

Fig 2. Foto de corte encefálico coronal passando pelos corpos mamilares, submetido a coloração de Green. 


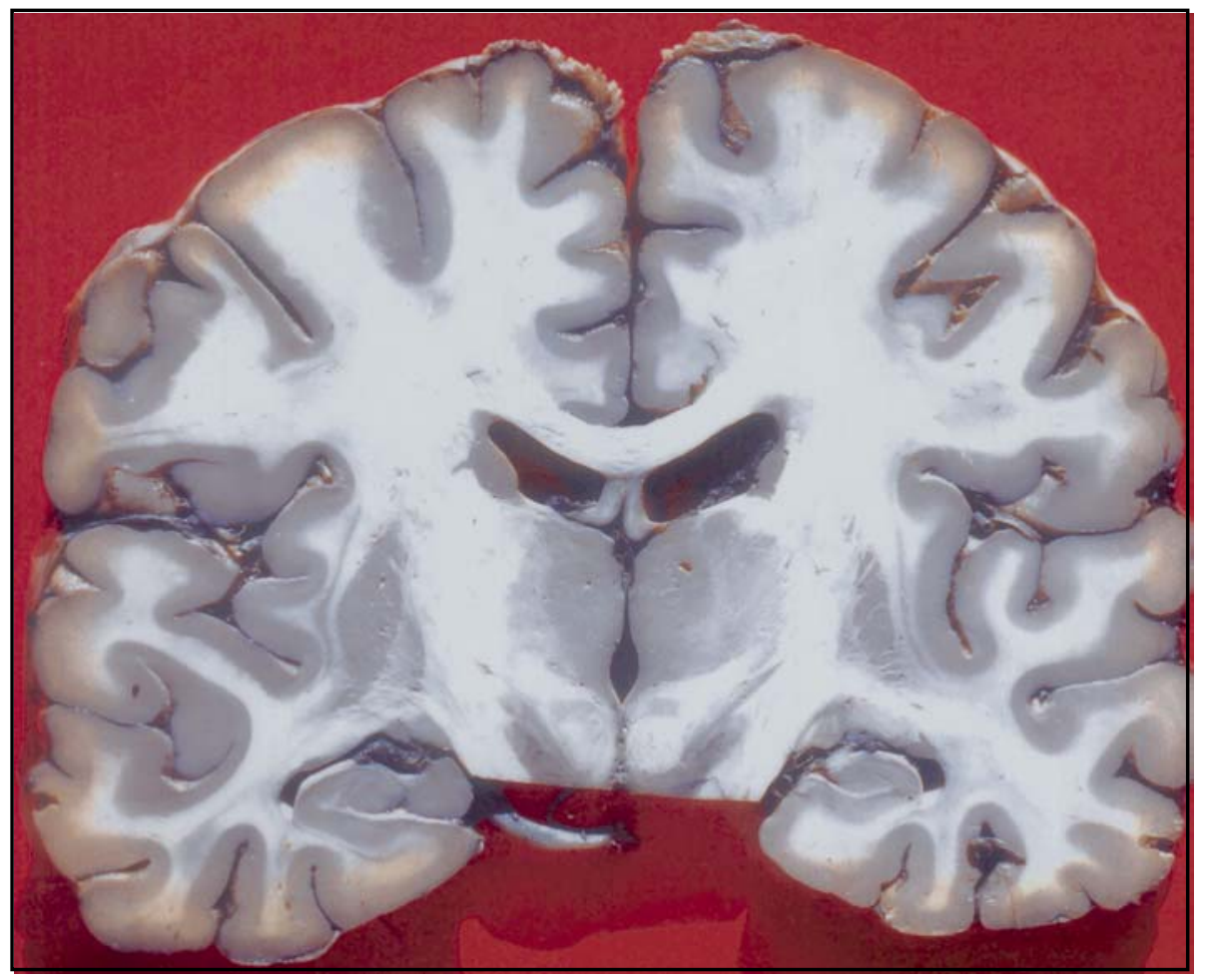

Fig 3. Foto de corte encefálico coronal passando pelos corpos mamilares, submetido a coloração de Mulligan.

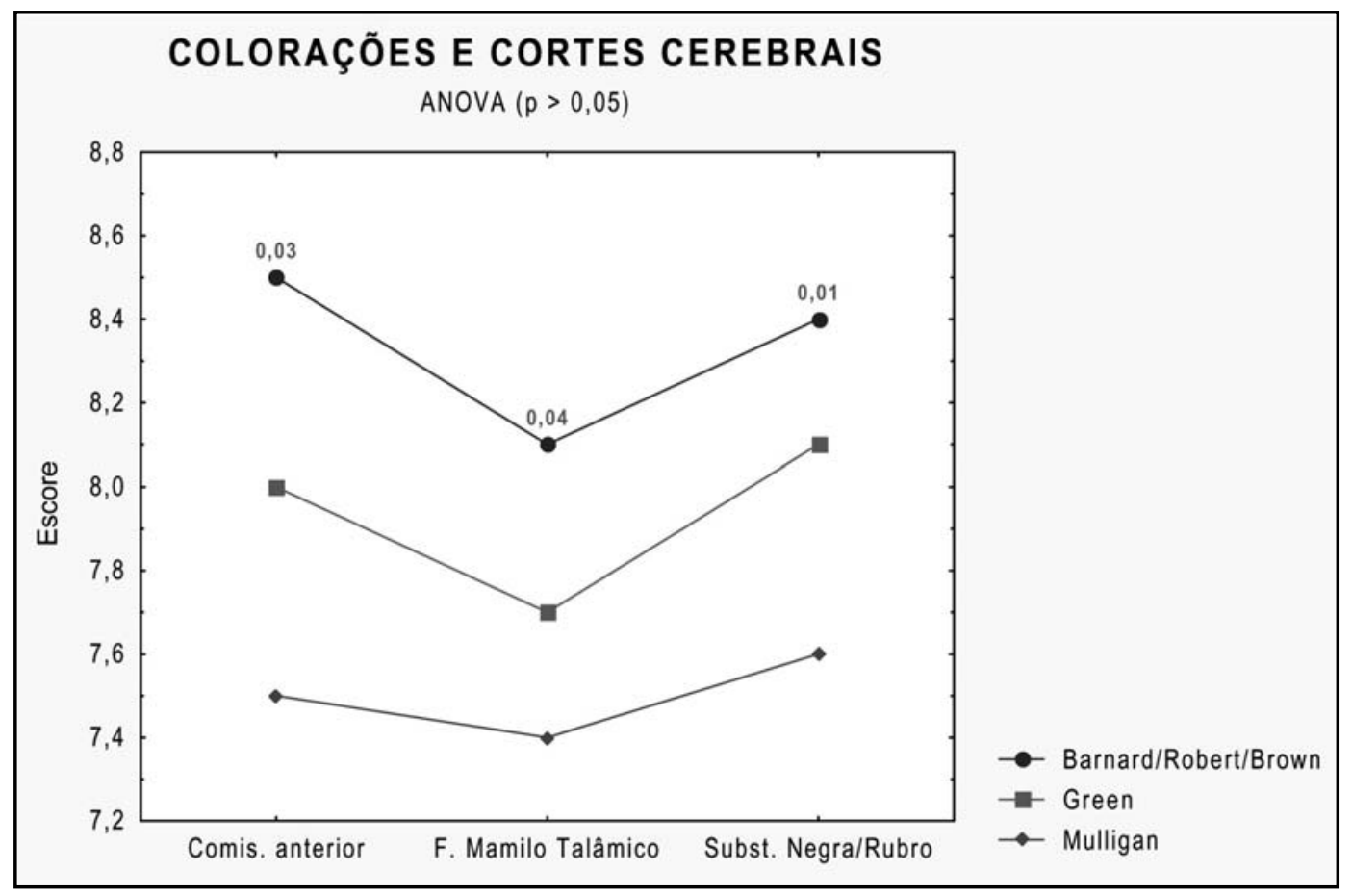

Fig 4. escore médio de cada técnica de coloração nos 3 cortes de encéfalo; a coloração de Barnard, Robert e Brown alcançou os escores mais elevados; os valores de $p$ indicados referem-se à diferença entre esta coloração e a coloração de Mulligan. 
outros locais de substância branca como a coroa radiada, a cápsula interna e a substância branca do lobo temporal. Avaliou-se a extensão e a tonalidade com que essa impregnação foi observada. Sabe-se que as técnicas de coloração de substância cinzenta podem apresentar a desvantagem de impregnar também a substancia branca em graus variados ${ }^{4}$. Procurou-se determinar qual das três técnicas realizadas mantinham menor área de substância branca impregnada pelo corante. Do mesmo modo, atribui-se pontuação de 0 a 3 para avalisar este critério. Nota 0 indica substância branca impregnada pelo corante em área superior a $75 \%$ da superfície total do corte; nota 1 refere-se à presença de substância branca impregnada pelo corante em área de 50 a 75\% de superfície total do corte; nota 2 impregnação pelo corante em área de 25 a $50 \%$ da superfície total; nota 3, em área menor que $25 \%$ da superfície total de corte.

Desta forma, estabeleceu-se classificação prática para a análise das técnicas utilizadas nesse estudo através da atribuição de pontuações para cada parâmetro citado.

Para cada corte foi realizado o somatório das pontuações obtidas nos três diferentes parâmetros, podendo a nota variar de 0 a 9 . Todos os dados coletados, digitados em planilha eletrônica (M icrosoft Excel $\left.{ }^{\circledR}\right)$, foram conferidos e exportados para o programa Statistica ${ }^{\circledR}$. As variáveis selecionadas para análise estatística foram inicialmente submetidas à avaliação de sua distribuição por meio de testes de normalidade, coeficiente de variação e análise de histogramas. Os dados de distribuição normal são apresentados por meio de médias e desvio padrão. Os testes estatísticos aplicados foram selecionados de acordo com a distribuição das variáveis e seu caráter independente, constituído de escores de 3 cortes anatômicos com 3 tipos de coloração de córtex cerebral. Para todos foram utilizados os testes bicaudais, considerando que as diferenças poderiam estar distribuídas para ambos os lados da curva, com nível de significância mínimo de $5 \%$. Para avaliar as possíveis diferenças entre as avaliações feitas sobre as colorações testadas foi aplicada a análise da variância (ANOVA). As diferenças foram posteriormente apontadas pela aplicação do teste de Duncan. A amostra foi estimada considerando um erro de tipo I máximo de $5 \%$ (alfa) e erro do tipo II máximo de $10 \%$, com um poder de teste estimado mínimo de $80 \%$.

\section{RESULTADOS}

Nos cortes realizados na região da comissura anterior, a coloração de Barnard, Robert e Brown (Fig 1) apresentou

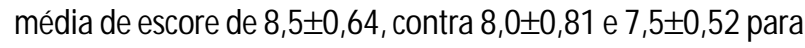
as colorações de Green (fig 2) e Mulligan (Fig 3), respectivamente. Esta diferença revelou-se significativa $(p=0,004)$. Quando analisadas isoladamente, houve diferença significante $(p<0,05)$ quando comparadas as colorações de Barnard, Robert e Brown com a de Mulligan; a coloração de Green mostrou-se intermediária, sem diferença estatística em relação às demais.

Nos cortes realizados na região do fascículo mamilotalâmico, a coloração de Barnard, Robert e Brown mostrou-se novamente superior, com escore médio de $8,1 \pm 0,73$, seguida da coloração de Green $(7,7 \pm 0,82)$, e finalmente da de Mulligan $(7,4 \pm 0,82)$, porém desta vez sem diferença significativa $(p=0,16)$. A diferença só se mostrou estatisticamente significante quando comparadas isoladamente as colorações de Barnard, Robert e Brown com a Mulligan.

Já na região da substância negra/núcleo rubro, a média dos escores da coloração de Barnard, Robert e Brown foi de $8,4 \pm 0,69$, a de Green $8,1 \pm 0,31$ e a de Mulligan 7,6 $6 \pm 0,61$, sendo esta diferença novamente significativa $(p=0,008)$. Analisadas isoladamente, a diferença revelou-se estatisticamente significante quando comparadas as colorações de Barnard, Robert e Brown com a de Mulligan.

Quando analisados os dados em conjunto, constata-se que a coloração de Barnard, Robert e Brown mostra-se mais eficaz principalmente quando comparada com a de Mulligan, a coloração de Green ocupa posição intermediária, com valores próximos aos níveis de significância estatística em relação à coloração de Green, ou seja, assemelha-se mais à coloração de Barnard, Robert e Brown (Fig 4).

\section{DISCUSSÃO}

0 grande desenvolvimento tecnológico de novos métodos de neuroimagem por tomografia computadorizada e por ressonância magnética de última geração têm evidenciado detalhes anatômicos muito precisos ${ }^{13-17}$. Há necessidade cada vez maior de estudo anatômico prévio para perfeito conhecimento das estruturas de substância cinzenta e branca ${ }^{18,19}$.

Os cortes encefálicos utilizados em estudo de anatomia apresentam estruturas muitas vezes de difícil identificação quando observadas a olho nu. As técnicas de coloração utilizadas em nosso estudo demonstraram-se eficazes ao permitirem melhor delimitação entre as diversas formações de substância cinzenta e de substância branca. Esta característica é uma das principais vantagens do emprego dos métodos de coloração, sendo analisada nos diversos cortes por meio do parâmetro 1.0 estudo neuroanatômico dos núcleos base, por exemplo, é muito facilitado uma vez que é nítida a separação existente entre os mesmos por uma fina camada de substância branca.

As técnicas de coloração apresentam também algumas desvantagens reveladas pela análise dos parâmetros 2 e 3.0 parâmetro 2 avaliava a presença de limite preciso e nítido entre substâncias cinzenta e branca. Em alguns cortes observou-se que a coloração ofuscava este limite diminuindo a nitidez da delimitação que há entre estas formações. $A$ análise do parâmetro 3, grau de impregnação da coloração em outros locais de substância branca, demonstrou uma das principais desvantagens destes métodos de coloração, ou seja, a substância branca pode ser afetada pelo corante. Através da atribuição de pontuações para os três parâmetros citados, obteve-se avaliação objetiva da qualidade da técnica de coloração empregada, uma vez que se consideram tanto as suas vantagens como desvantagens.

Em nosso estudo, de acordo com os três parâmetros estabelecidos, o método de coloração de Barnard, Robert e Brown revelou-se melhor que o método de Green, e este, por sua vez, melhor que o método de Mulligan. Contudo, a 
realização da técnica de Barnard, Robert e Brown é mais trabalhosa que a de Green, uma vez que necessita de quatro soluções diferentes, sendo uma delas aquecida a 65 ㅇ․ A técnica de Green exige, para sua realização, apenas três soluções que não necessitam de aquecimento. Além disso, a realização da técnica de Barnard, Robert e Brown é mais demorada que a de Green, com duração média de nove minutos para corar um corte encefálico, enquanto que a de Green tarda apenas três minutos. Com relação à técnica de Mulligan, sua realização é relativamente trabalhosa (necessita de três soluções, sendo uma aquecida a $65^{\circ} \mathrm{C}$ ) e demorada ( 5 minutos), porém a qualidade da coloração obtida com este método é inferior quando comparada aos outros dois.

A técnica de Barnard, Robert e Brown revelou-se a mais eficaz na diferenciação entre as substâncias cinzentas e branca do encéfalo quando comparada às demais pelos parâmetros estabelecidos. Recomendamos que os laboratórios de anatomia empreguem esta técnica como método de coloração de cortes encefálicos, apesar de ser uma técnica mais trabalhosa e de realização mais demorada.

Sugerimos a realização de novos estudos comparativos de técnicas de coloração de peças do sistema nervoso central através de análise de outros métodos de coloração e da atribuição de novos parâmetros de avaliação.

\section{REFERÊNCIAS}

1. Arruda WO. Oneurônio e o tecido nervoso. In Meneses MS. Neuroanatomia aplicada. Rio de Janeiro: Guanabara-Koogan, 1999:2-27.

2. Teive HAG. Núcleos da base, estruturas correlatas e vias extrapiramidais. In Meneses MS. Neuroanatomia Aplicada. Rio de Janeiro: GuanabaraKoogan, 1999:224-236.

3. Meneses MS, Teive HAG. Doença de Parkinson: aspectos clínicos e cirúrgicos. Rio de Janeiro: Guanabara-Koogan, 1996.

4. Rodrigues. H. Técnicas Anatômicas. 2.Ed. Vitória: Arte Visual, 1998.

5. Mainland D. Uber makroskopiche faerburg von Gehirnprraeparaten mit Berlinblau. Anat Anz 1926;65:85-88.

6. Kondratjew NS. Nerven Farben Methud. Anat Anz 1926;12-13:257-273.

7. Mulligan JH. A method of staining for macroscopic study. J Anat London 1931;65:472-476.

8. Barnard JW, Robert JO, Brown JC. A simple macroscopic staining, and mouting, procedure for wet section from cadaver brains. Anat Rec 1949;105:1-17.

9. Hilderbrand M. Anatomical preparation. Berkeley, University Press, 1968.

10. Jacobowits DM. Human brain slicer: a method for cutting coronal slices of fresh and fixed human brains. Res Bull 1994;33:461-463.

11. Opeskin K. A device for cutting brain slices. Biotech Histochem 1994;59:253-256.

12. Pai KS. A simple and inexpansive slicer for preparation of brain slices. J Neurosci Meth 1991;37:209-214.

13. Blackstad TW. Computer methods in neuroanatomy: determining mutual orientation og whole neuronal arbors. Comput Biol Med 1993;23:227-250.

14. Greitz T. Use of computerized brain atlas in magnetoencephalographic activation studies. Neuroreport 1994;5:449-452,.

15. Kazarnovskaya MI. 3-D computer model of subcortical structures of human brain. Comput Biol Med 1991;21:451-457.

16. Sundsten JW. Videodisc animation of 3-D computer reconstruction of the human brain. J Biocommun 1991;18:45-49.

17. Tiede UA. A computerized tridimensional atlas of the human skull and brain. AJNR 1993;14:551-559.

18. Greitz T. A computerized brain atlas: construction anatomical content, and some applications. J Comput Assist Tomogr 1991;15:126-38.

19. Losner A. Computer models of the brain - how far can they take us? J Theor Biolv 1994;17:61-73. 